East African Medical Journal Vol. 85 No. 7 July 2008

PREVALENCE OF HEPATITIS C VIRUS AND ITS GENOTYPES AMONG A COHORT OF DRUG USERS IN KENYA

T. Muasya, MSc (Public Health), Research Scientist, Kenya Medical Research Institute, Centre for Virus Research, P.O. Box 54840-00200, Nairobi, Kenya, W. Lore, MD, FRCP, Director, Institute of Health Research and Services, P.O. Box 2159600505 Nairobi, Kenya, K. Yano, MD, PhD, Medical Doctor, H. Yatsuhashi, MD, PhD, Medical Doctor, National Hospital Organisation Nagasaki Medical Centre Clinical Research Center, WHO Collaborating Centre for Reference and Research on Viral Hepatitis, Kubara 2-1001-1 Omura City, Nagasaki 856-8562, Japan, F.R. Owiti, MBChB, MRCPsy (UK), Psychiatrist, College of Health Sciences, University of Nairobi, P.O. Box 19676-00202, Nairobi, Kenya, M. Fukuda, MSc (Virology), Research Scientist, M.Y. Tamada, MSc (Virology), Research Scientist, National Hospital Organisation Nagasaki Medical Centre Clinical Research Centre, WHO Collaborating Centre for Reference and Research on Viral Hepatitis, Kubara 2-1001-1 Omura City, Nagasaki 856-8562, Japan, J. Kulundu, Cert. (Medical Lab. Sci), Medical Laboratory Technician, J. Tukei, MSc (Virology), Research Scientist and F.A. Okoth, MBChB, MMed, Director, Kenya Medical Research Institute, Centre for Virus Research, P.O. Box 54840-00200, Nairobi, Kenya

Request for reprints to: Mr. T. Muasya, The Kenya Medical Research Institute, Centre for Virus Research, P.O. Box 54840-00200, Nairobi, Kenya

\title{
PREVALENCE OF HEPATITIS C VIRUS AND ITS GENOTYPES AMONG A COHORT OF DRUG USERS IN KENYA
}

\author{
T. MUASYA, W. LORE, K. YANO, H. YATSUHASHI, F.R. OWITI, M. FUKUDA, M.Y. TAMADA, \\ J. KULUNDU, J. TUKEI and F.A. OKOTH
}

\begin{abstract}
Background: Prevalence of hepatitis $C$ virus and that of its main genotypes varies between the worlds geographic regions. The risk factors for infection with HCV include blood transfusion, tattoing and injecting drug use.

Objectives: To examine the prevalence of $\mathrm{HCV}$ and determine its main genotypes among a cohort of drug users in Kenya.

Design: A laboratory based study.

Setting: Hepatitis research laboratory in the Centre for Virus Research at the Kenya Medical Research Institute, Nairobi.

Subjects: Three hundred and fourteen male and 19 female intravenous and non-intravenous drug users aged between 15-55 years.

Results: Seventy four (22.2\%) out of 333 samples tested positive for anti-HCV. Sixty nine out of the 74 serum samples were assayed for HCV RNA and $38(55.5 \%)$ were positive. The RNA positive samples were further subjected to sequencing and $19(73 \%)$ of the samples were classified as genotype la, while seven ( $27 \%$ ) samples were classified as genotype 4 . Genotypes 2, 3, 5 and 6 were not identified in this study.

Conclusions: These results demonstrate a high HCV infection prevalence among this cohort of drug users $(22.2 \%)$ as compared to that of the general population, which is estimated to be $0.2-$ $0.9 \%$. The study also confirms the presence of at least two major genotypes among Kenyan drug users (genotypes 1 and 4).
\end{abstract}

\section{INTRODUCTION}

Hepatitis C prevalence varies between geographic regions and is estimated to affect over 170 million worldwide. In the majority of cases, HCV infection gives rise to an acute illness; $80 \%$ of such cases develop into chronic hepatitis. The virus cannot be cultured in vitro and this has hampered investigations. The HCV 
genome consists of a positive-sense RNA molecule approximately $9.5 \mathrm{~kb}$ in length. In terms of genome organisation, $\mathrm{HCV}$ is a member of the flaviviridae and has now been placed in a new monotypic genus in this family. The genome contains a long open reading frame, which encodes a polyprotein of about 3000 amino acids. There is a non-coding region (NCR) of 324-341 nucleotides at the $5^{\prime}$ end and a $3^{\prime}$ NCR of variable length including a poly $(\mathrm{U})$ tract. The nucleotide sequence of $\mathrm{HCV}$ is highly variable, the most divergent isolates sharing only $60 \%$ nucleotide sequence homology. There is an association between certain genotypes and disease severity in the liver, i.e. cirrhosis and primary liver cancer as well as the response to interferon treatment (2). There is therefore a need for further research on the natural variation of $\mathrm{HCV}$ and isolates and their distribution worldwide. Isolates have now been grouped into six main genotypes, each with several subtypes, based on sequence data (3). Genotypes 1-3 account for almost all infections in Japan, U.S.A and Europe, genotype 4 is prevalent in Egypt and Democratic republic of Congo, genotype 5 in South Africa and genotype 6 in Hong Kong. It is not clear whether immunity to one type prevents subsequent infection with another, but there is some evidence that various genome types differ in their biological properties. The risk factors for infection with hepatitis $\mathrm{C}$ include blood transfusions, tattoing and injecting drug use which currently, is regarded as one of the most important factors. The parental route of infection seems to be most prevalent, with high rates of infection seen in intravenous drug abusers, haemophiliacs and recipients of unscreened blood transfusions. The possibility of sexual transmission cannot be eliminated, but if it occurs, the risk seems to be very low. Vertical transmission of $\mathrm{HCV}$ in utero and perinatally has also been reported, but again, appears to be rare. Injecting drug use is currently the most important risk factor for infection with hepatitis $C$, resulting in high prevalence rates of hepatitis $\mathrm{C}$ among injecting drug users. The practice of injecting shared drugs, in which drug users prepare, divide and inject portions of a drug solution, is a means of transmitting $\mathrm{HCV}$, $\mathrm{HBV}$ and HIV. In Kenya, the prevalence of HCV has not been well established. The reason is that there has not been an established gold standard diagnostic system. The purpose of this study was to examine the prevalence of $\mathrm{HCV}$ and determine the genotypes of $\mathrm{HCV}$ among a cohort of drug users in Kenya.

\section{MATERIALS AND METHODS}

This survey was a WHO drug injecting study and KEMRI-JICA jointly assisted in the laboratory assay part of the project. The subjects from a wide spectrum of age and social background were recruited in the year 2000 from a population of drug users either in their residential areas, prisons or outpatient clinics in Nairobi, which is the largest city in Kenya. They were then regularly followed for interview and blood collection in the field. The drug user population consisted of intravenous drug users, who included current injectors (injected drugs within the last six months), ex-injectors (not injected in the previous six months) and non-injectors (subjects whose mode of drug consumption is other than injection) (Table 1). Subject participation was not limited to a particular drug. After informed consent was obtained, the subjects completed a multi question survey questionnaire which focused on demographic information and topic areas associated with hepatitis $C$ transmission (intravenous drug use, sexual history, cultural practices, used needlesharing behaviours, medical history). The 333 subjects who gave informed consent were bled at various locations and the serum obtained was tested for anti-HCV, HBsAg and anti-HIV by Murex, KEMRI Hepcell and Vironostika respectivelly. For HCV, Murex anti-HCV version 4.0 EIA (Murex Biotech SA Ltd, Kyalami, South Africa) was used. The reactive anti-HCV samples were then confirmed using a third generation recombinant immuno blot assay (RIBA) For HBsAg, Latex Biotech particle agglutination kit (Biotech laboratories) was used and confirmation done using the KEMRI HepCell II reverse passive haemagglutination kit (developed at Kenya Medical Research Institute, Kenya) was used while for HIV, Vironostika (ELISA) kit was used and confirmation done using enzygnost.

HCV RNA determination: Sixty nine out of the seventy four Anti-HCV positive samples were determined for HCV-RNA due to volume limitations. The samples were stored at $-20^{\circ} \mathrm{C}$ until assay time. The purity of the template RNA is important since non nucleic acid components of serum or plasma can inhibit/contaminate the cDNA PCR reaction. Complementary DNA was synthesised with a reverse transcriptase, random primer, $5 x$ buffer, $\mathrm{R}$-nase inhibitor and dNTPs which were incubated 
for 90 mins at $37^{\circ} \mathrm{C} .45 \mathrm{ul}$ of the cDNA amplification mixture plus 5 ul of the cDNA making a total of 50ul were then subjected to PCR. Polymerase chain reaction (POR assay) with primers located on the conserved 5' non-coding region. Antisense primer (pst 98-115) and sense primer (pst 285-312) with Taq polymerase, 70 cycles of PCR were performed as follows;

Denaturation for 15 seconds at $95^{\circ} \mathrm{C}$

Annealing for 20 seconds at $64^{\circ} \mathrm{C}$

Extension for 1.5 mins at $72^{\circ} \mathrm{C}$

A 10ul aliquot of the PCR product was then subjected to $2 \%$ agarose gel electrophoresis. The gels were stained with ethidium bromide and results analysed and examined for the presence of bands of the size expected i.e. 215 base pairs.

Sequencing and phylogenetic analysis: Complementary DNA was synthesised and the cDNA mixture subjected to PCR with primers located on the NS5B region (8278-8618), 40 cycles for two and a half hours. A 5 ul aliquot of the PCR product was subjected to $1 \%$ agarose gel electrophoresis at $100 \mathrm{~V}$ for 40 minutes. The expected product is 382 base pairs. Sequencing reactions were performed with ABI PRISM Big Dye terminator cycle sequencing ready reaction kit, and the the ABI PRISM 3100 genetic analyzer (Applied Biosystems) according to the manufacturers protocol. The nucleotide sequences of the determined Kenyan HCV strains (335 nucleotides) were aligned using clustaw W. A phylogenetic tree was constructed using the Neighbour-joining (N-J) method. The 37 sequences of other isolates used for the phylogenetic analysis were retrieved from DDBJ / EMBL/ Gene bank.

\section{RESULTS}

The total number of subjects were 333. The intravenous drug users were $145(43.5 \%)$ of the total population with $94(64.8 \%)$ of them being current drug injectors and $51(35.2 \%)$ being ex-drug injectors (Table 1).

Table 2 shows that among all age groups, current drug users were more than the ex-users. The 11-20

Table 1

Characteristics and survey responses of recruited subjects

\begin{tabular}{ll}
\hline Characteristic & Frequency \\
\hline $\begin{array}{l}\text { Sex }(\mathrm{M} / \mathrm{F}) \\
\text { Marital status }\end{array}$ & $314 / 19$ \\
$\quad \%$ married & $60 / 333(18 \%)$ \\
$\begin{array}{l}\text { Intravenous drug use } \\
\% \text { with any history of usage }\end{array}$ & $145 / 333(43.5 \%)$ \\
$\begin{array}{l}\text { Non- intravenous drug use } \\
\% \text { with no history of drug injection }\end{array}$ & $188 / 333(56.5 \%)$ \\
$\begin{array}{l}\text { Current intravenous users } \\
\quad \text { Injected within the past six months) }\end{array}$ & $94 / 145(64.8 \%)$ \\
$\begin{array}{l}\text { Past intravenous users } \\
\quad \text { (Not injected within the past six months) }\end{array}$ & $51 / 145(35.2 \%)$ \\
\hline
\end{tabular}

Table 2

Age groups in relation to status

\begin{tabular}{lrrrr}
\hline $\begin{array}{l}\text { Age group } \\
\text { (years) }\end{array}$ & Current users & \multicolumn{2}{c}{ Ex-users } \\
\hline $11-20(\mathrm{n}=26)$ & No. & $(\%)$ & No. & $(\%)$ \\
$21-30(\mathrm{n}=186)$ & 11 & 42.3 & 4 & 15.3 \\
$31-40(\mathrm{n}=99)$ & 52 & 27.9 & 31 & 16.6 \\
$41-50(\mathrm{n}=19)$ & 38 & 38.3 & 13 & 13.1 \\
$51-60(\mathrm{n}=3)$ & 0 & 0 & 2 & 10.5 \\
& 3 & 100 & 0 & 0 \\
\hline
\end{tabular}


years age group had $11(42.3 \%)$ current users as compared to four (15.3\%) ex-users. The 21-30 year age group had $52(27.9 \%)$ current users as compared to $31(16.6 \%)$, the $31-40$ year age group had $38(38.3 \%)$ current users as compared to $13(13.1 \%)$ ex-users, the 41-50 year age group had no current users and only two (10.5\%) ex-users while the 51-60 year age group had three current users and no ex-users.

Figure 1 shows infection rates of $\mathrm{HCV}, \mathrm{HBV}$ and HIV among different age groups. The age range was 14-54 years. Majority of the drug users 186 (55.8\%) were in the 21-30 year age group. The 51-60 year age group had the least number of drug users three $(0.9 \%)$. HCV infection was high among the 11-20 year age group which had eight (30.7\%), then 21-30 which had $41(22 \%)$ followed by the 31-40 year age group which had 18 (18.2\%). The 41-50 year age group had the lowest percentage of HCV infection (5.26\%). A considerable decrease in $\mathrm{HCV}$ infection rates with increase in age is notable. HBV infection rates were highest among the 31-40 year age group which had seven $(7.1 \%)$ followed by the $41-50$ year age group which had one $(5.26 \%)$, then 11-20 year age group and 21-30 year age groups which had one (3.8\%) and $\operatorname{six}(3.2 \%)$ respectively. The 51-60 year age group had no cases of HBV. As for HIV, the 11-20 and 21-30 year age groups had high infection rates of seven (26.9\%) and $42(22.5 \%)$ while the $41-50$ year age group had the lowest three $(15.7 \%)$. A decrease in infection rates with an increase in age is also noted here.

Out of the 333 samples, 74, 15 and 74 were positive for anti-HCV, HBsAg and anti-HIV respectively. Out of the 74 anti-HCV reactive samples, five could not be analysed by PCR due to volume limitations. A proportion of 38 of $69(55.5 \%)$ of HCV antibody positive samples was viraemic. Of the 38 established HCV viraemic cases, 33 (87\%) were intravenous drug users.

Figure 1

Infection among different age groups

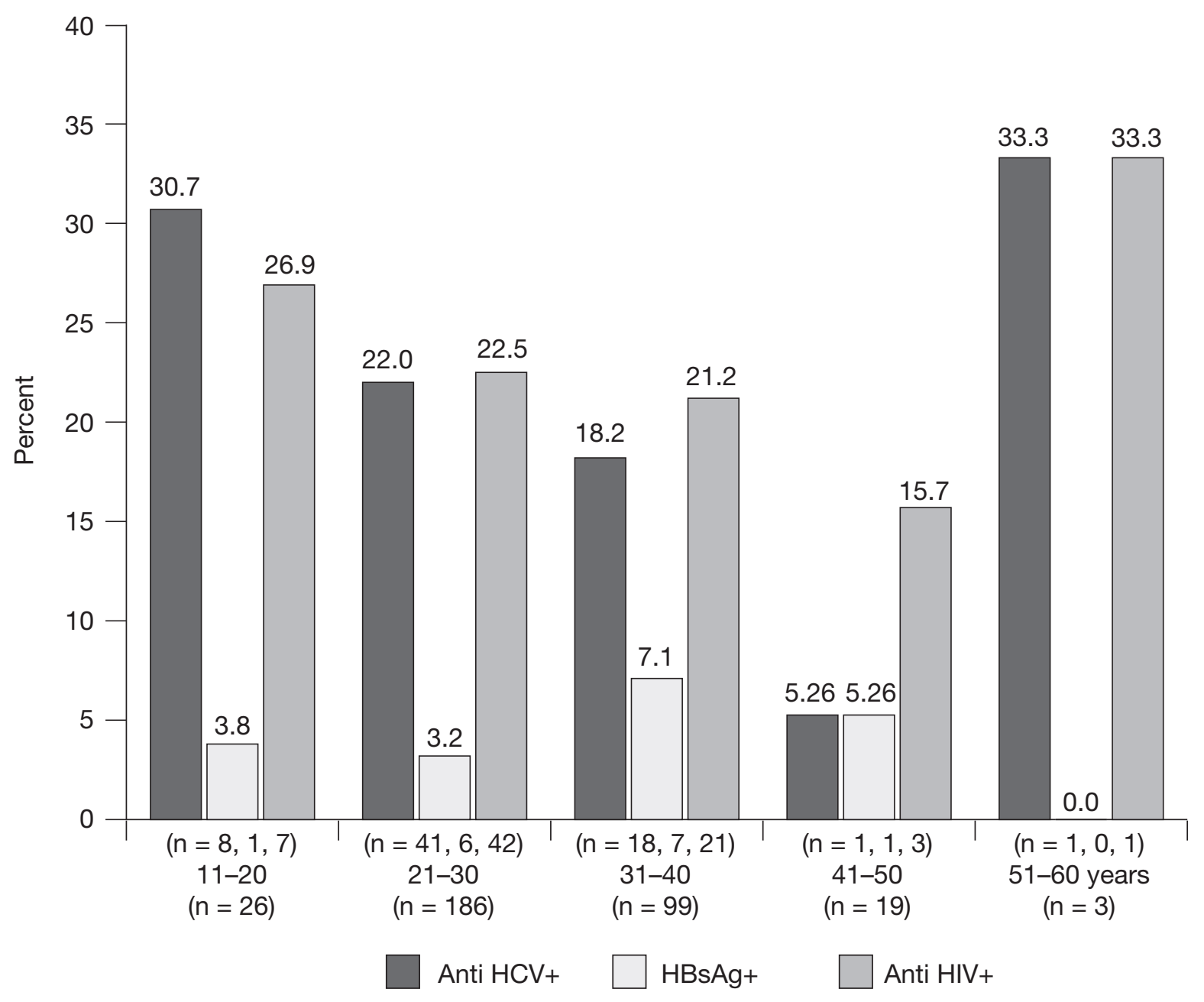


Among the drug injectors, $57(60.6 \%)$ of the current injectors were positive for anti-HCV as compared to the ex-injectors who were $10(19.6 \%)$. This difference is significant $\mathrm{p}<0.0001$. Infection with HBV was high with six $(6.4 \%)$ among the current injectors while that of the ex-injectors was three $(5.8 \%)$. This was insignificant $\mathrm{p}>0.9999$. About 47 $(50 \%)$ of the current drug users tested positive for anti-HIV as compared to only five $(9.8 \%)$ of the ex-injectors. Here the difference was significant $p<0.0001$ (Figure 2). The number of co-infection with both HCV and HIV among the injecting drug users is $47,43(12.9 \%)$ of them being current drug users and four $(1.2 \%)$ being ex-users. The numbers were low two $(0.6 \%)$ among the non-injecting drug users. This is significant $\mathrm{p}<0.0001$.

Of the 333 subjects, 314 (9.2\%) were males and 19 $(5.7 \%)$ were females. The males who were positive for anti-HCV were $61(19.4 \%)$ while the females were eight $(42.6 \%)$, a significant difference $\mathrm{p}=0.0352$. For HBV, $15(4.8 \%)$ males tested positive and all females tested negative. This was insignificant $p>0.9999$. For
anti-HIV, $63(20 \%)$ males tested positive compared to $11(57.9 \%)$ females, a significant difference $\mathrm{p}=$ 0.0005 (Table 3).

In the sequence analysis of the 38 viraemia positive serum samples, 26 of them were successfully sequenced. A phylogenetic tree was constructed by the neighbour-joining method using published $\mathrm{HCV}$ sequences and those determined in this study. The 26 Kenyan sequences were aligned with $37 \mathrm{HCV}$ reference strains from the genebank database. The characterisation of the viral genotypes indicated that of the HCV strains, 19 (73\%) were of genotype la while seven $(27 \%)$ were genotype 4 (Figure 3). The nucleotide sequence homologies between the samples K170, K112, K115, K126, K154, K171, K184, K197, K198, K26, K28, K38, K51, K55, K56, K61, K77, K78 and K89 in genotype 1a ranged from 96-100\%. While that of the samples K159, K137, K136, K114, K108, K193 and K30 in genotype 4 ranged from $96.1 \%-100 \%$. The nucleotide sequences homologies between samples in genotype 1 and those in genotype 4 ranged from $67-70.2 \%$.

Figure 2

$H C V, H B V$ and HIV infection rates among different drug user populations. (Current injectors $n=94$, ex-injectors $n=51$, non-injectors $n=188$ )

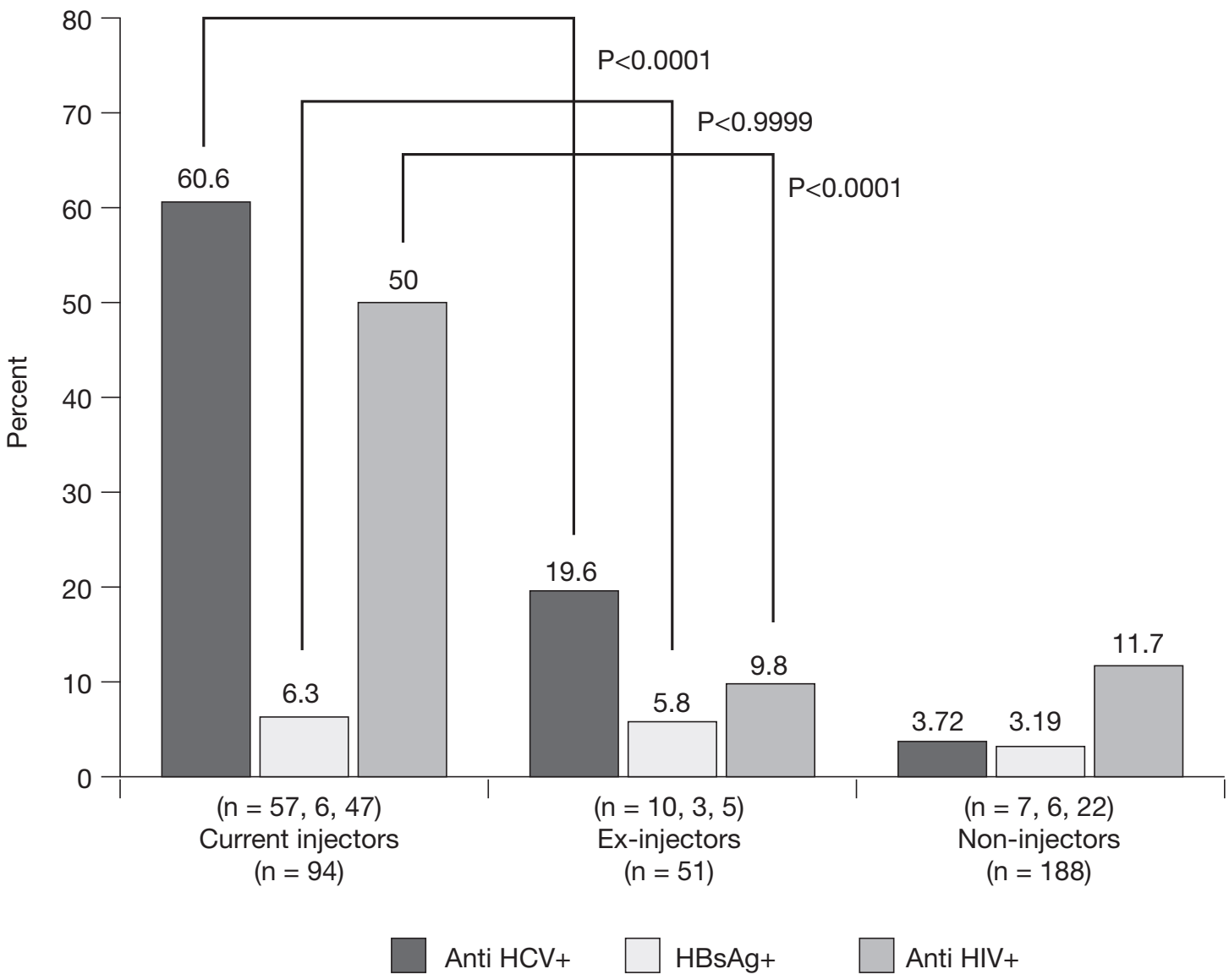


Genotype 1 subjects had a mean age of 26 years while that of genotype 4 subjects was 31 years. There were 18 males and one female in genotype 1 while in genotype 4 there were six males and one female. The number of injectors were 18 and 5 while the non-injectors were one and five for genotypes 1 and 4 respectively. Among the injectors, the current ones were 17 and 4 as compared to one and one for ex-injectors for genotypes 1 and 4 respectively. There is no statistical significant difference between genotype and gender $p=0.4738$, genotype and drug consumption mode $p=0.1669$, genotype and injection status $\mathrm{p}=0.1433$ (Table 4).

Table 3

Infection in relation to gender

\begin{tabular}{|c|c|c|c|c|c|c|}
\hline Gender & $\begin{array}{l}\text { Anti-HCV + } \\
\text { No. }(\%)\end{array}$ & $\mathrm{P}$-value & $\begin{array}{l}\text { HBsAg + } \\
\text { No. }(\%)\end{array}$ & P-value & $\begin{array}{l}\text { Anti-HIV + } \\
\text { No. }(\%)\end{array}$ & P-value \\
\hline Males $(\mathrm{n}=314)$ & 6119.4 & $\mathrm{p}=0.0352$ & $15 \quad 4.8$ & $\mathrm{p}=0.9999 \mathrm{NS}$ & $63 \quad 20$ & $p=0.0005$ \\
\hline Females $(\mathrm{n}=19)$ & $8 \quad 42.1$ & & 0 & & 1157.9 & \\
\hline
\end{tabular}

\section{Figure 3}

Phylogenetic tree of HCV strains from Kenyan isolates with reference strains. The 26 Kenyan sequences were aligned with $37 \mathrm{HCV}$ reference strains from the gene bank data base. The six major lineages of HCV are indicated by the bold face characters along the branches

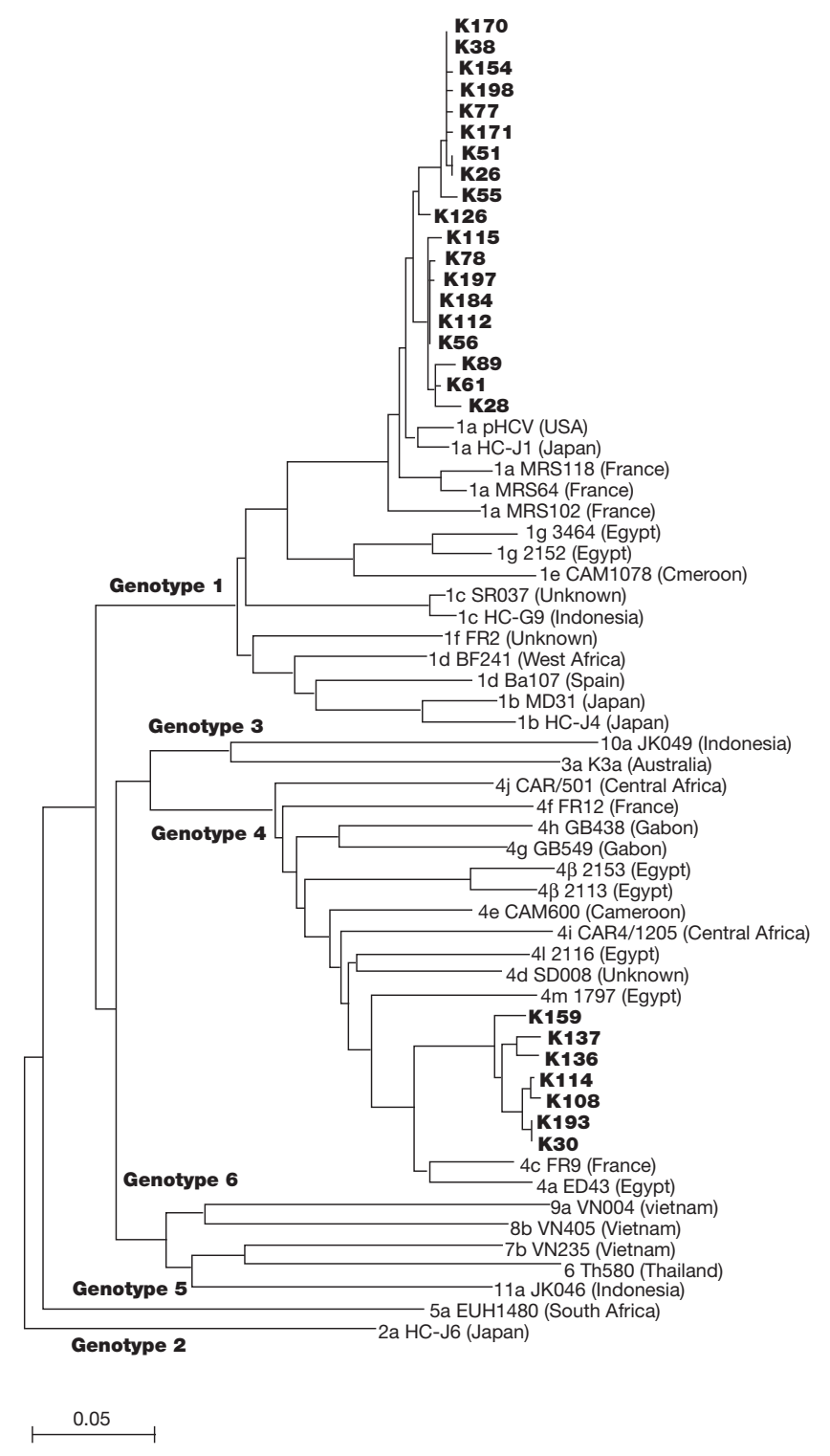


Table 4

Comparison between genotypes 1 and 4

\begin{tabular}{lccc}
\hline Status & Genotype 1a $(\mathrm{n}=19)$ & Genotype $4(\mathrm{n}=7)$ & P-value \\
\hline Age (mean) & 26 & 31 & \\
Gender (M/F) & $18 / 1$ & $6 / 1$ & $\mathrm{p}=0.4738$ \\
Injector/non-injector & $18 / 1$ & $5 / 2$ & $\mathrm{p}=0.1669$ \\
Current/ex-user & $17 / 1$ & $4 / 1$ & $\mathrm{p}=0.1433$ \\
\hline
\end{tabular}

\section{DISCUSSION}

From this study we observed that there were more non-intravenous drug users than the intravenous users. In the intravenous drug user group, the current users were more than the ex-users. However, the difference in HCV infection between the current injectors and ex-injectors in the drug injectors group was significant. In the United States, the most common route of current transmission of $\mathrm{HCV}$ is intravenous drug use (3). This is also evident in this study where the current users were more infected than the ex-users. Apart from the spread of the $\mathrm{HCV}$ through other routes, needle sharing could contribute enormously to constant re-introduction of new viral strains into the bodies of the already infected individuals.

Surprisingly, intravenous drug use risk did not increase with age. It would seem likely that older people have been infected longer and therefore have had more chances to transmit the disease. The 21-30 year age group had the most drug users. At these ages, there is a lot of peer group pressure and excitement in trying new things in life like alcohol, drugs and cigarettes. There is also a lot of influence and idleness because it is at this age when most people have just completed college and are frustrated by lack of securing jobs in major urban centres. From this study we also observe that infection with HCV was high among the 21-40 year age groups. A cohort effect for HCV infection has also been suggested in some United States population based studies showing a similar epidemiological pattern of $\mathrm{HCV}$ infection. Indeed a recent national U.S survey showed that most (65\%) persons with HCV infection were 30-39 years of age. This shows that in the US, the transmission of HCV had occurred in the recent past, primarily among young adults as a result of drug use and high risk sexual behaviour (3). The low prevalence of anti-HCV antibodies among older persons in the United States is most likely due to a cohort effect and the risk of acquiring HCV infection lower in the distant past rather than the recent past. In Kenya, the risk was the same, higher in the recent past than the distant an observation that is different from that observed and reported in Cameroon (4) and Italy (5).

Viraemia with $\mathrm{HCV}$ was detected in majority of the intravenous drug users. Probably it would have been detected in more samples were they to be assayed immediately after collection, the reason being denaturation of the nucleic acids during storage and transportation of the samples from one laboratory to another for different analytical procedures. Determination of absence of viraemia in this study was based on a single negative PCR test, which cannot rule out viraemia at an earlier stage of infection.

Transmission between different sexes is often assumed to be sexual. However other routes of transmission cannot be ruled out. Males comprised the majority of the drug users. This is evident in many societies whereby the male population is usually dominant when it comes to substance abuse, including alcoholism and others. Infection rates with HCV and HIV were high among the female population in this study.

Isolates from all over the world have now been grouped into six main genotypes, one to three accounting for most infections in Japan, U.S.A and Europe, four and five in Africa and six in Asia (6). The prevalent genotype 1 found in this study has a worldwide distribution while genotype 4 is believed to be distributed widely in African countries. Our data agree with a previous study carried out in Cameroon (4) whereby genotypes $1 \mathrm{a}, 1 \mathrm{~b}$ and 4 were found with genotype 1 being the dominant one. Additional studies should thus be performed in neighbouring countries so as to reveal the real distribution of $\mathrm{HCV}$ genotypes. This study is the first to describe HCV genotypes among drug users in Kenya. Subtype la was predominant. This prevalent genotype has been found in Europe, 
Japan and the United States. These are different from those found in the African continent i.e Egypt, Central Africa and South Africa where genotypes 4, 4 and 5 are dominant respectively. Presence of genotype 4 in this study agrees with a study (7) carried out in Central Africa whereby genotype 4 is the most prevalent. Another study carried out in Egypt reported similar findings whereby Egyptian HCV epidemic is composed of multiple lineages of genotypes 1 and 4 (8). In Nigeria, presence of genotypes 1 and 4 was reported among healthy blood donors and children of pre-school age (9). Presence of genotype 1 has also been reported in a study carried out in Morocco (Northern Africa) among haemodialysis and chronically infected patients (10). More studies need to be done in Africa to establish the true distribution of hepatitis $C$ genotypes especially now that genotype 1 has been documented in Africa.

\section{ACKNOWLEDGEMENTS}

The authors wish to thank; JICA, for financial support; Nagasaki Medical Centre and Dr Y. Omoto for technical support; WHO, for facilitating this project and Director, KEMRI, for allowing publication of this paper.

\section{REFERENCES}

1. Karuru, J.W., Lule, G.N., Joshi, M. and Anzala, O. Prevalence of $\mathrm{HCV}$ and $\mathrm{HCV} / \mathrm{HIV}$ co-infection among in-patients at the Kenyatta National Hospital, Nairobi. Kenya. East Afr. Med. J. 2005; 82: 170-172.
2. Pozzato, G., Morretti, M., Croce, L.S., Sasso, F. et al. Interferon therapy in chronic Hepatitis $C$ virus evidence of different outcome with respect to different viral strains. J. Med. Virol. 1995; 45: 445-450.

3. Alter, M.J., Marigolds, H.S., Krawczynski, K., et al. The natural history of community-acquired hepatitis $\mathrm{C}$ in the United States. The Sentinel Counties Chronic non-A, non-B Hepatitis Study Team. N. Engl. J. Med. 1992; 327: 899-905.

4. Njouom, R., Parquie, C., Ayouba, A., et al. High rate of HCV infection and predominance of genotype 4 among elderly inhabitants of a remote village of the rain forest of South Cameroon. J. Med. Virol. 2003; 71: 219-225.

5. Distefano, L., Strofollini, T., Ferraro, D., et al. Endemic $\mathrm{HCV}$ infection in a Sicilian town,further evidence for atrogenic transmission. J. Med. Virol. 2002; 67: 339-334.

6. Simmonds, P., Holmes, E.C., Cha, T.A., et al. Classification of Hepatitis $\mathrm{C}$ virus into six major genotypes and a series of subtypes by phylogenetic tree analysis. Hepatol. J. 1995; 21: 570-583.

7. Li-Zheku, Xu., Larzul, D., Delaporte, E., et al. Hepatitis C virus genotype 4 is highly prevalent in Central Africa (Gabon). J. Gen. Virol. 1994; 75: 2393-2398.

8. Ray, S.C., Arthur, R.R., Carella, A., et al. Genetic epidemiology of hepatitis $C$ throughout Egypt. J. Infectious Dis. 2000; 182: 698-707.

9. Oni, A. and Harrison, T.J. Genotypes of hepatitis C virus in Nigeria. J. Med. Virol. 1996; 49: 178-186.

10. Benani, A., El-Turk, J., Benjelloun, S., Sekkat, S. et al. Hepatitis C genotypes in Morocco. J. Med. Virol. 1997; 52: 396-398. 